\title{
The Current Status of Traffic Nitrogen Oxides Pollution in Cluj - Napoca
}

\author{
Ioan OROIAN ${ }^{1}$, Antonia ODAGIU ${ }^{1 *}$, Ilie COVRIG ${ }^{2}$, Călin Ovidiu SAFIRESCU ${ }^{1}$ \\ ${ }^{1}$ Faculty of Agriculture. University of Agricultural Science and Veterinary Medicine,Cluj - Napoca, \\ România \\ ${ }^{2}$ Faculty of Horticulture. University of Agricultural Science and Veterinary Medicine,Cluj - Napoca, \\ România \\ *Corresponding author: antonia.odagiu@usamvcluj.ro \\ Bulletin USAMV series Agriculture 72(2)/2015 \\ Print ISSN 1843-5246; Electronic ISSN 1843-5386 \\ DOI 10.15835/buasvmcn-agr: 11744
}

\begin{abstract}
Assessing air quality in high urbanized areas and finding solution for most important pollutants (NOx, CO, $\mathrm{SO}_{2}$, VOC, $\mathrm{PM}, \mathrm{O}_{3}$, and heavy metals emissions) remains a challenge for authorities and public in aimed areas. The harmful effects upon humans and environmental health is the reason of all concerns. Lots of studies have been developed, in this area, worldwide. Majority of these state that traffic is the most important source of air pollution in crowded cities. The aim of this study consists in establishing the status quo of NOx pollution status in Cluj Napoca. NOx air pollution was quantified during a year period (2013), in two locations correspondent to high traffic and position of automatic air quality monitoring stations placed by The Agency of Environmental Protection Cluj. Parameters were monitored using a mobile equipment. The average values of the analyzed parameters are different function of monitoring point. We noticed statistically significant differences between monitoring points, but in all cases the average concentrations are over the maximum admitted annual limit, $30 \mathrm{ppb}$, respectively. Further research and more intense concerns are needed from both public and authorities, in order to diminish the nitrogen oxides quantity in environmental air.
\end{abstract}

Keywords: air quality, traffic, urban areas, basic statistics.

\section{INTRODUCTION}

Assessing air quality one of the most important issues that concerns urban authorities. The most important pollutants, which occur in large amounts in urban areas are: $\mathrm{NOx}, \mathrm{CO}, \mathrm{SO}_{2}$, VOC, $\mathrm{PM}, \mathrm{O}_{3}$ and heavy metals as $\mathrm{Cd}, \mathrm{Hg}, \mathrm{Cu}, \mathrm{Pb}$, etc. (Atkinson et al., 2004; Oroian et al., 2009). Their presence remains a challenge for urban authorities and inhabitants of these areas, also because complex reactions they are subject in atmospheric air (Atkinson et al., 2004; Varotsos et al., 2014). The harmful effects upon humans and environmental health is the reason of all concerns (Oroian et al., 2009; Williams and Carslaw, 2011).

In this respect we mention that global concerns in this area resulted in a document called, "The
Gothenburg Protocol" signed in 1999, which aims to state the main rules in order to abate acidification, eutrophication and ground-level ozone, until 2010, where Romania is also part (http://www.unece. org/env/lrtap/multi_h1.html). This protocol was modified in 2012, by including Parts engagements concerning mitigation of air pollutants emissions until 2020, compared to 2005 (http://www.anpm. ro/ro/web/apm-cluj/raportare-anuala/). Within Gothenburg Protocol and modified provisions, we may also find measures for NOx abatement. Concerning Romania specific case, they state that up to 2020, our country must mitigate NOx emission by $45 \%$ compared to their amounts in $2005(309,056)$, which means they must be lower than the threshold of 170,000 t/year (http://www. 
anpm.ro/ro/web/apm-cluj/raportare-anuala/). According to the previously cited document, in our country, NOx emissions are produced in majority by traffic (38.01\%), and thermic and production of electric energy (24.73\%).

Lots of studies have been developed, in this area, worldwide Grice et al., 2009; Lefebvre et al., 2014; Villena et al., 2012). Majority of these state that traffic is the most important source of air pollution in crowded cities. One of the most important aspects of this situation concern the decrease of NOx emissions, since adopting "The Gothenburg Protocol" . So, if in UK these emissions decreased from 2004 up to 2009, in range of 1-2\% (Carslaw et al., 2011), in Romania, they recorded about 28\% decrease (http://www.anpm.ro/ro/ web/apm-cluj/raportare-anuala/).

Establishing the status quo of NOx pollution status in two important areas from Cluj Napoca, one industrial type other of urban type characterized by heavy traffic, during 2013, is the aim of our study.

\section{MATERIALS AND METHODS}

The experiments were carried out in ClujNapoca, town with a population of 304,509 inhabitants, according to last census from 2013, is a first rank municipality, being the second urban agglomeration in Romania, after Bucharest, the capital of the country

Two areas were taken into consideration and monitored, in order to quantify NOx air pollution. These areas, also are automatically monitored by The Cluj-Napoca Environmental Protection Agency (CNEPA). They are located in Dâmboviței St. - Grigorescu District, and Cluj-Napoca center Nicolae Bălcescu College (Fig. 1).

The NOx concentrations were monitored using a mobile equipment, in the same week day, at the same hour intervals $12.00-14.00$, respectively. Data from the Cluj-Napoca Environmental Protection Agency Report for 2013 - Air Quality are also used in order to compare our monitoring results with official data.

Basic statistics and Box-Plot diagrams were used in order to emphasize the monthly NOx means in monitored points, and dispersion parameters. ANOVA test was implemented for calculation of significance of differences between monitoring places, and industrial area located in Dâmboviței St. (Grigorescu District), and an urban

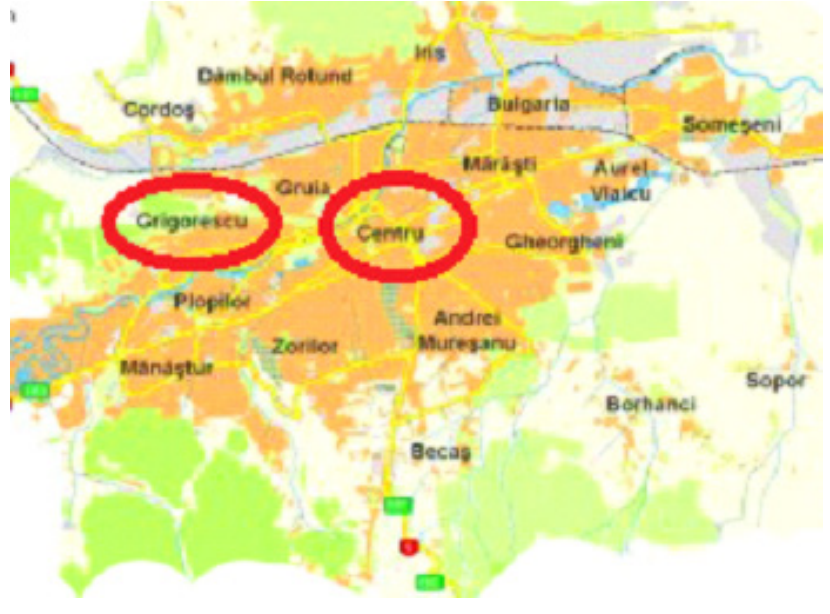

Fig. 1. Cluj-Napoca map (https://www.google.ro/ search?q=cluj-napoca\&biw=1127)

area characterized by high traffic, Cluj-Napoca center (Nicolae Bălcescu College), respectively. STATSTICA Software, v.8.0 for windows, was used for data processing.

\section{RESULTS AND DISCUSSION}

The monthly means of NOx values are different function of monitoring point. The highest means recorded in experimental point located in Dâmboviței St. (Grigorescu District), an industrial area (Tab. 1, Fig. 2), are reported in autumn and winter months, December (55.33 ppb), January (47.67 ppb), November (45.67 ppb), October (42 ppb), and February (41. ppb). The lowest NOx average value (16.67 ppb), is reported in July (Tab. 1, Fig. 2).

The Box-Plot diagram concerning NOx emissions recorded in Dâmboviței St. located in Grigorescu District, in industrial area, emphasize a normal distribution of data, but with highest dispersion on April and June, and lowest in February, March, and May (Fig. 2).

Concerning monthly means of NOx values reported in town center (Nicolae Bălcescu College) in 2013, we note, similarly with results recorded in experimental point located in Dâmboviței St. (Grigorescu District), that they correspond to winter and autumn months (Tab. 2, Fig. 3). Thus, they correspond to the following values: 86.67 ppb (January), 84.67 ppb (October), $81 \mathrm{ppb}$ (December), 78.67 ppb (February and November). The lowest NOx average value (44.67 ppb), is reported in May (Tab. 2, Fig. 3). 
The Box-Plot diagram concerning NOx emissions recorded in town centre nearby Nicolae Bălcescu College emphasize a normal distribution of data, but with highest dispersion on January, March and August, and lowest in July, and December (Fig. 3).

The differences emphasized in dispersion sizes, reported in specific months of the year, may be explained by climatic conditions (temperature, dew point, atmospheric pressure, wind direction and velocity, humidity, rainfall regimen, etc.) specific for each period.

If we take into consideration the yearly mean values of NOx emissions recorded in both monitored points, of $33.92 \mathrm{ppb}$ in experimental point located in Dâmboviței St. (Grigorescu

Tab. 1. Basic statistics for the evolution of NOx occurrence in Cluj-Napoca, monitored in Dâmboviței St. (Grigorescu District), during 2013 (ppb)

\begin{tabular}{ccccc}
\hline Month & $\mathrm{N}$ & Mean, $\mathrm{ppb}$ & Standard deviation & Standard error of mean \\
\hline January & 5 & 47.67 & 1.45 & 0.65 \\
\hline February & 5 & 41.00 & 0.58 & 0.26 \\
\hline March & 5 & 37.00 & 0.58 & 0.26 \\
\hline April & 5 & 30.00 & 2.89 & 1.30 \\
\hline May & 5 & 20.67 & 0.33 & 0.15 \\
\hline June & 5 & 26.33 & 3.18 & 1.43 \\
\hline July & 5 & 16.67 & 1.76 & 0.79 \\
\hline August & 5 & 20.33 & 0.88 & 0.39 \\
\hline September & 5 & 24.33 & 1.86 & 0.83 \\
\hline October & 5 & 42.00 & 1.53 & 0.69 \\
\hline November & 5 & 45.67 & 1.20 & 0.54 \\
\hline December & 5 & 55.33 & 1.45 & 0.65
\end{tabular}

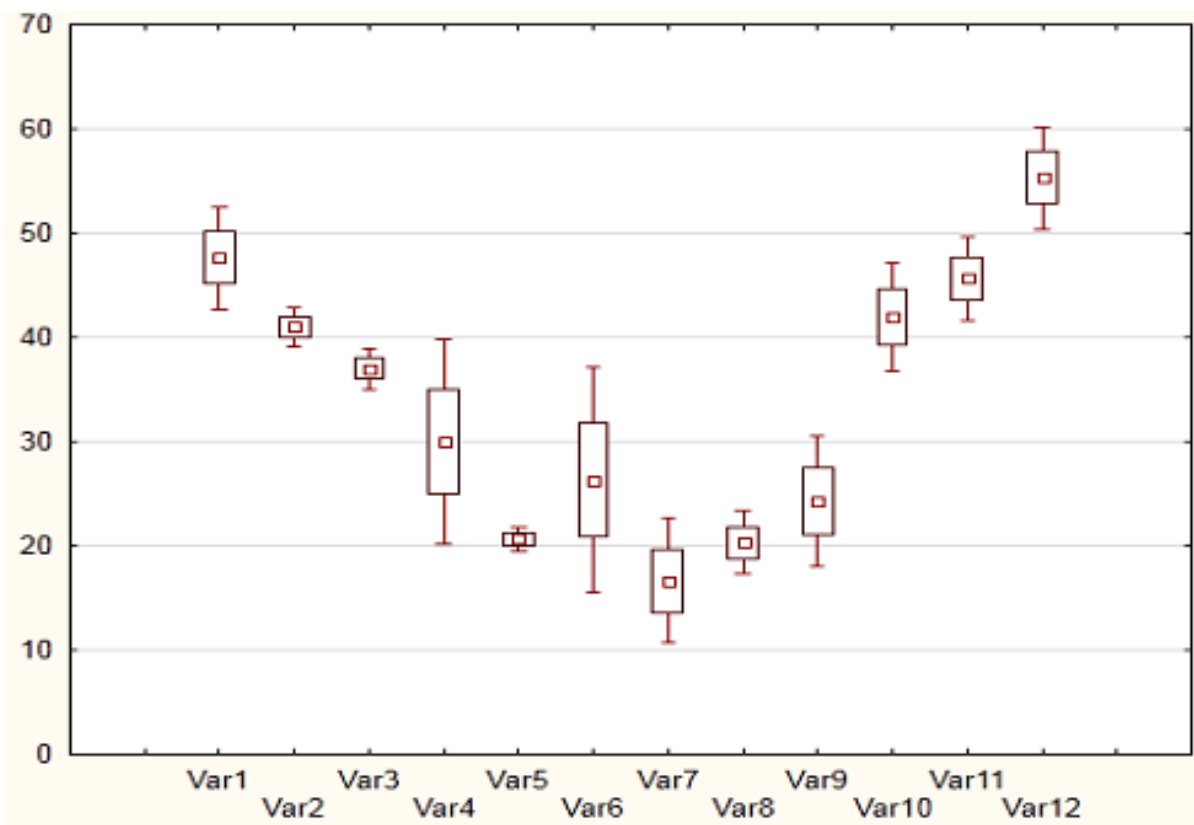

Var 1-January; Var 2-February; Var 3-March;Var 4-April;Var 5-May;Var 6-June;Var 7-July; Var 8-August;Var 9-September;

Var 10-October;Var 11-November;Var 21-December;

Fig. 2. The Box-Plot diagram concerning NOx emissions recorded in Dâmboviței St. (Grigorescu District) - industrial area 
District), and 66.94 ppm in town center (Nicolae Bălcescu College) in 2013, respectively, we note normal distributions, but the difference between means, of $33.92 \mathrm{ppb}$ is very significant, at $\mathrm{p}<$ 0.001 (Fig. 4).

These differences between the yearly means of NOx emissions in monitored points are determined by the specific of the areas. The monitoring point located in Dâmboviței St. (Grigorescu District) is one of industrial type with moderated traffic. Thus it can be explained the difference between the mean value of $33.92 \mathrm{ppb}$ NOx reported for this area in 2013, compared with 66.94 ppm NOx, mean value reported for NOx emissions, in 2013, in town center (nearby Nicolae Bălcescu College), area characterized by heavy traffic.

Tab. 2. Basic statistics for the evolution of NOx occurrence in Cluj Napoca, monitored town centre (Nicolae Bălcescu College), during 2013

\begin{tabular}{ccccc}
\hline Month & N & Mean & Standard deviation & Standard error of mean \\
\hline January & 5 & 86.67 & 7.64 & 1.98 \\
\hline February & 5 & 78.67 & 3.21 & 0.83 \\
\hline March & 5 & 67.33 & 6.66 & 1.72 \\
\hline April & 5 & 54.33 & 4.04 & 1.04 \\
\hline May & 5 & 44.67 & 4.51 & 1.17 \\
\hline June & 5 & 52.00 & 4.00 & 1.04 \\
\hline July & 5 & 51.00 & 2.00 & 1.35 \\
\hline August & 5 & 51.00 & 6.56 & 1.70 \\
\hline September & 5 & 73.33 & 4.16 & 1.08 \\
\hline October & 5 & 84.67 & 5.03 & 1.30 \\
\hline November & 5 & 78.67 & 3.21 & 0.83 \\
\hline December & 5 & 81.00 & 2.00 & 0.52 \\
\hline
\end{tabular}

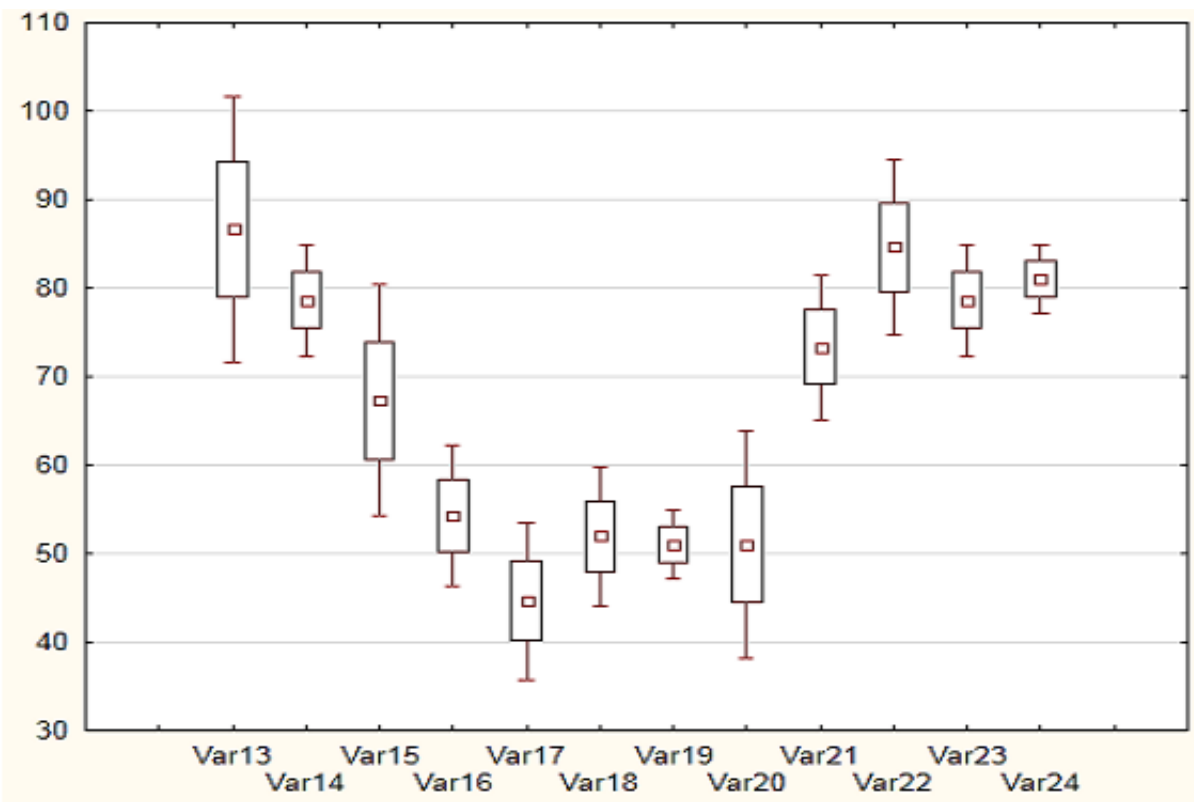

Var 13-January; Var 14-February; Var 15-March;Var 16-April;Var 17-May;Var 18-June;Var 19-July; Var 20-August; Var 21-September; Var 22-October;Var 23-November;Var 24-December;

Fig. 3. The Box-Plot diagram concerning NOx emissions recorded in town centre (Nicolae Bălcescu College) - urban area 
These results are in concordance with situation reported in our country concerning the difference between NOx emission amounts in industrial areas and traffic (http://www.anpm. ro/ro/web/apm-cluj/raportare-anuala/). In our study, the NOx mean emission by 2013 recorded in an industrial area Dâmboviței St. (Grigorescu District) is by $49.32 \%$ lower compared with NOx mean emission by 2013, recorded in town center (nearby Nicolae Bălcescu College), which is an area characterized by heavy traffic.

If we compare the means of NOx emissions in 2013 in both monitored points with those reported by the Cluj-Napoca Environmental Protection Agency (Fig. 5), we notice differences. The NOx mean emission by 2013 resulted from our study for the industrial area located in Dâmboviței St. (Grigorescu District), of 33.92 ppm NOx, is by $21.75 \%$ higher compared to the value reported by

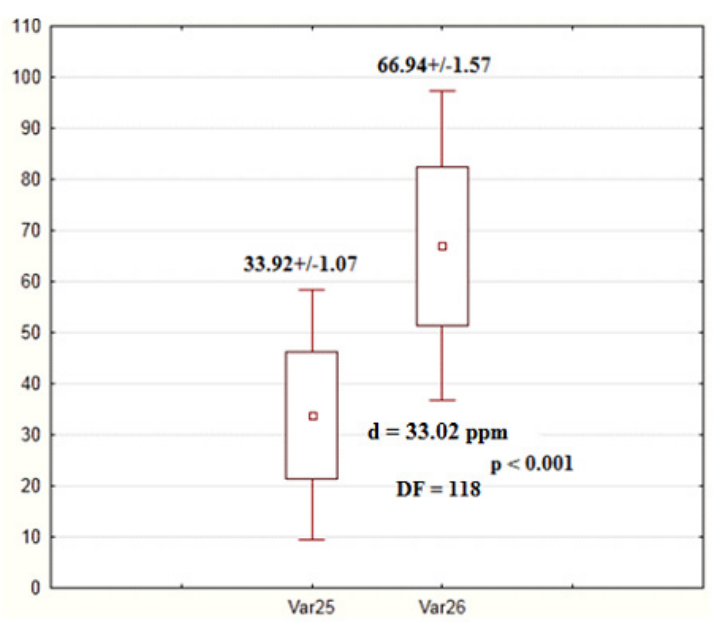

Var 25- Dâmboviței St. (Grigorescu District); Var 26- town center (Nicolae Bălcescu College)

Fig. 4. The Box-Plot diagram concerning NOx emissions recorded in studied monitoring places located in Cluj-Napoca

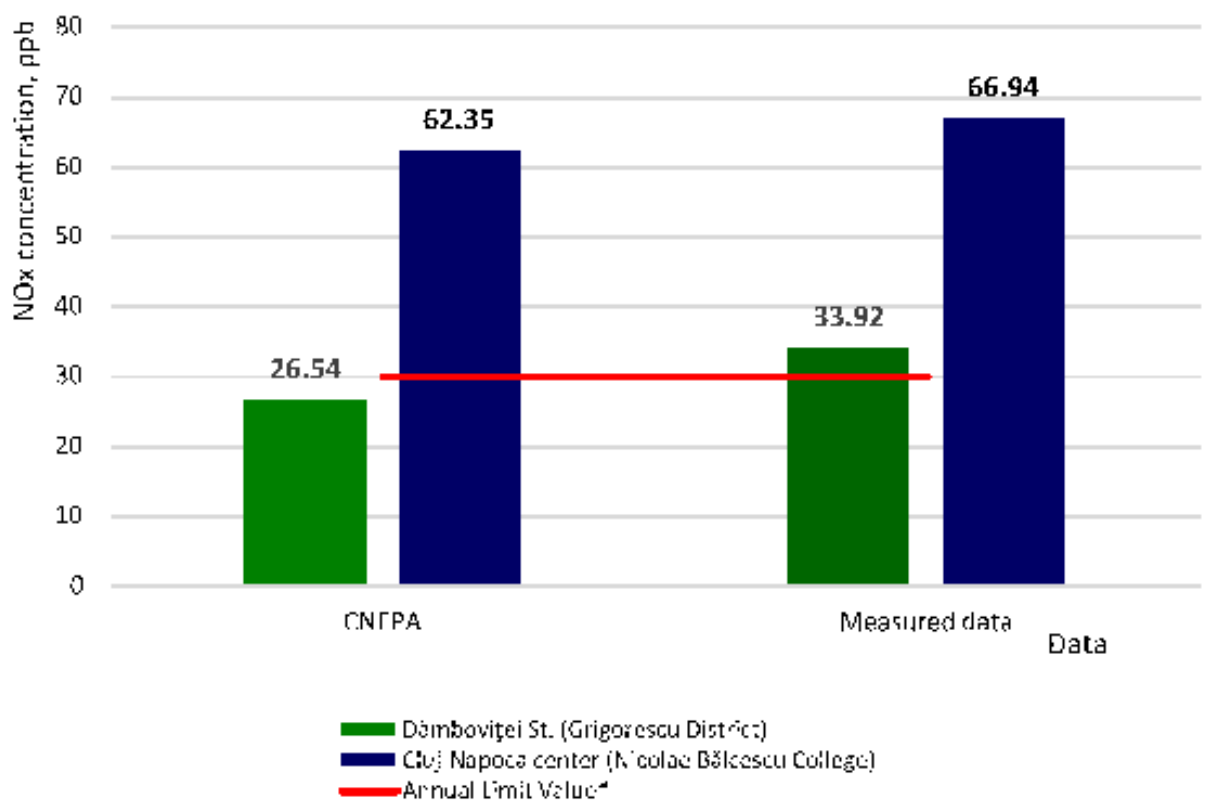

Fig. 5. The means of NOx emissions recorded in studied monitoring places located in Cluj-Napoca, according to measured data of experimental results, and data reported by The Cluj-Napoca Environmental Protection Agency (CNEPA) 
Cluj-Napoca Environmental Protection Agency for the same year, meaning $26.54 \mathrm{ppm}$ NOx.

Concerning NOx mean emission by 2013, resulted from our study for town center (nearby Nicolae Bălcescu College), of 66.94 ppm NOx, is by $6.86 \%$ higher compared to the value reported by Cluj-Napoca Environmental Protection Agency for the same year, meaning 62.35 ppm NOx (Fig. 5). Results of both studies show that NOX emissions expressed as yearly means are superior to annual limit value, of $30 \mathrm{ppb}$, established by Romanian legal frame in Law 104/2011 (Fig. 5).

These differences between the results of our study and those reported by Cluj-Napoca Environmental Protection Agency, concerning the mean NOx amounts expressed by year 2013 in both monitored points may be explained by the sampling procedure. If Cluj-Napoca Environmental Protection Agency sampling is performed continuously with automatic air quality monitoring stations, our study developed a discontinuous sampling protocol, performed with a mobile device, in rush hours. Thus, the biggest NOx emission means resulted from our study are justified.

In above described sampling conditions, the low difference $(6.86 \%)$ between the yearly mean of NOx emissions reported by our research and that reported by Cluj-Napoca Environmental Protection Agency, emphasize that by entire day interval the Cluj-Napoca urban areas are characterised by heavy traffic.

\section{CONCLUSIONS}

The NOx emissions monitored in two important areas of Cluj-Napoca town, by ours study and official institution represented by the Cluj-Napoca Environmental Protection Agency, in the year 2013, expressed as yearly means, have superior values compared with limit value stated by present national regulations, which is in amount of $30 \mathrm{ppm}$.

The mean value of NOx emissions reported by our study is of $33.92 \mathrm{ppm}$ for Dâmboviței St. (Grigorescu District), and $66.94 \mathrm{ppm}$ for town center (nearby Nicolae Bălcescu College). The mean value of NOx emissions reported by ClujNapoca Environmental Protection Agency are 26.54 ppm for Dâmboviței St. (Grigorescu District), and $62.35 \mathrm{ppm}$ for town center (nearby Nicolae Bălcescu College), the differences being explained by sampling approaches.
Further research and more intense concerns are needed from both public and national and regional authorities, in order to diminish the nitrogen oxides quantity in environmental air.

\section{REFERENCES}

1. Atkinson R, Baulch DL, Cox RA, Crowley JN, Hampson RF Jr, Kerr JA, Hynes RG, Jenkin ME, Kerr JA, Rossi MJ, Troe J (2004). Summary of Evaluated Kinetic and Photochemical Data for Atmospheric Chemistry, Volume I-gas phase reactions of Ox, HOx, NOx and SOx species. Atmospheric Chemistry and Physics 2004, 4:1461-1738.

2. Carslaw D, Beevers S, Westmoreland E, Williams M, Tate J, Murrells T, Stedman J, Li Y, Grice S, Kent A, Tsagatakis I (2011). Trends in NOx and NO emissions and ambient measurements in the UK. http://www. accent-network.org/ accent_documents/Draft_NOx _NO2_trends_report.pdf

3. Grice S, Stedman J, Kent A, Hobson M, Norris J, Abbott J, Cooke S (2009). Recent trends and projections of primary NO2 emissions in Europe. Atmospheric Environ, 43:2154-2167.

4. Lefebvre W, Vanpoucke C, Fierens F, Janssen S, Degraeuwe $\mathrm{B}$, Mensink C (2014). The Influence of the Changing $\mathrm{NO}_{\mathrm{x}}$ Split for Compliance to the European Limit Values in Urban Areas. Air Pollution Modeling and its Application, XXIII: 391-394

5. Oroian I (2010). Air Pollution, Omrigon GmbH, Viena, Austria, www.omrigon.com

6. Oroian I, Paulette L, Iederan C, Braşovean I, Burduhos P, Balint C (2009). Modalities of PM10 and PM2.5 Quantification in Environmental Air Using the Standardized Method, ProEnvironment/ProMediu, 2(3): $3-7$

7. Varotsos CA, Ondov JM, Efstathiou MN, Cracknell AP (2014). The local and regional atmospheric oxidants at Athens (Greece). Environmental Science and Pollution Research 6 (21): 4430-4440

8. Villena G, Bejan I, Kurtenbach R, Wiesen P, Kleffmann J (2012). Interferences of commercial NO2 instruments in the urban atmosphere and in a smogchamber. Atmos Meas Tec 2012, 5:149-159. doi:10.5194/amt-5-149-2012.

9. Williams ML, Carslaw DC (2011). New directions: Science and policy - out of step on NOX and NO2? Atmos. Environ., 45:3911-3912.

10. *** (1999). The Gothenburg Protocol to Abate Acidification, Eutrophication and Ground-level Ozone. http://www.unece.org/env//rtap/multi_h1.html

11. ** (2011). Law 104/2011 concerning the quality of ambient air, Romanian Official Gazette, no. 452 from 28 June 2011 [in Romanian\}.

12. ${ }^{* * *}$ (2014). Report concerning environmental state, in the County of Cluj. http://www.anpm.ro/ro/web/apm-cluj/ raportare-anuala/ [in Romanian].

13. http s: / / w w w. go ogle.ro/search? q = clu jnapoca\&biw $=1127$ 